\title{
Dissipation of Acephate and Methamidophos Residues on Brinjal (Solanum melongena L.) and Okra (Abelmoschus esculentus L.)
}

\author{
Soudamini Mohapatra*, Gourishankar Manikrao, Lekha Siddamallaiah, \\ Radhika Buddidhathi, Nagapooja Yogendraiah Matadha
}

Pesticide Residue Laboratory Indian Institute of Horticultural Research, Hessaraghatta Lake P.O., Bangalore 560089, Karnataka, India

Received: 1 September 2016

Accepted: 20 October 2016

\begin{abstract}
This study reports on the dissipation of acephate residues on brinjal and okra and the formation of the metabolite methamidophos. The QuEChERS method in conjunction with gas chromatography (GC) and gas chromatography-mass spectrometry (GC-MS) was used for analyzing acephate and methamidophos in brinjal and okra. The limit of detection (LOD) and limit of quantification (LOQ) were 0.003 and $0.01 \mathrm{mg}$ $\mathrm{kg}^{-1}$ for both compounds, respectively. The recoveries were between $76.6-99.5 \%$ with the relative standard deviation (RSD) between 3.2-11.8\% $(\mathrm{n}=6)$. The measurement uncertainty (MU) was between $9.9-17.5 \%$ at $95 \%$ confidence level. The initial residues of acephate were 8.61 and $13.63 \mathrm{mg} \mathrm{kg}^{-1}$ on brinjal, and 8.44 and $15.05 \mathrm{mg} \mathrm{kg}^{-1}$ on okra from treatments at the standard and double doses of 560 and 1,120 $\mathrm{g}$ a.i. ha ${ }^{-1}$, respectively. The concentration of methamidophos increased up to the third day on brinjal and okra and decreased thereafter. Methamidophos was more persistent than acephate. The pre-harvest intervals (PHI) required for dissipation of the combined residues of acephate and methamidophos to below the European Union maximum residue limits were 47 days for brinjal and 25 days for okra. The results of the study can be utilized for use of acephate in plant protection of brinjal and okra.
\end{abstract}

Keywords: acephate, gas chromatography (GC), gas chromatography mass spectrometry (GC-MS), methamidophos, residues

\section{Introduction}

Brinjal (also known as eggplant and aubergine) and okra (lady's finger) are the two most common and popular vegetable crops grown extensively throughout India. India is the largest producer of okra in the world [1]. The major

*e-mail:soudamini_mohapatra@rediffmail.com insect pests of brinjal are shoot and fruit borer (Leucinodes orbonalis Guenee), hadda beetle (Epilachna spp.), Jassid, (Amrascabiguttulabiguttula Ishida), aphid (Aphis gossypii Glover), stem borer (Euzopheraperticella Ragonot), white fly (Bemisiatabaci Gennadius), and the lace wing bug (Urentiusechinus Distant) [2]. The brinjal shoot and fruit borer causes shading of flower buds and reduces the brinjal yield, causing up to $70 \%$ damage to the crop at fruiting stage and making it unfit for human consumption 
[3-4]. Okra plants are attacked by a large number of insects during different growth stages. The major insect pest of okra is the fruit borer, which directly reduces the yield of marketable fruits [5].

Acephate (O,S-dimethyl acetylphosphoramidothioate) is an important systemic organophosphorus insecticide widely used in agriculture. Methamidophos (O,S-dimethyl phosphoramidothioate), a toxic metabolite of acephate, is a widely used organophosphorus insecticide with systemic properties and is effective against chewing and sucking insects. Methamidophos is much more toxic than acephate. The acute dermal toxicity for methamidophos $\mathrm{DL}_{50}$ in rats is $130 \mathrm{mg} \mathrm{kg}^{-1}$, and that of acephate $2,000 \mathrm{mg} \mathrm{kg}^{-1}$ [6]. Acephate was rapidly translocated and incorporated into plants when taken up from soil. It is primarily metabolized into methamidophos in plants and in leaves, and equaled $2-10 \%$ of the soil-applied acephate [7]. Methamidophos is a more potent organophosphate than acephate [8]. Acephate was most effective against shoot and fruit borer of brinjal [9-10]. Acephate is used in combination with other insecticides for control of insect pests of brinjal and okra [11-12]. It is also used individually for control of a large number of insect pests of okra, including fruit borer [5]. Acephate is commonly detected in honey, spices, and vegetables [13-15]. The residue of acephate in vegetables is of serious concern because it is gradually metabolized to more toxic methamidophos, which may be hazardous to human health [16]. Dissipation of acephate on brinjal has been studied in a different agro climatic zone in India where residues of methamidophos are not reported [17]. Information on the dissipation of acephate on okra is scarce. The present study was carried out to study dissipation of acephate on brinjal and okra and its transformation to methamidophos. The analytical method used for analysis of acephate and methamidophos on brinjal and okra was validated as per SANCO (2013) [18].

\section{Materials and Methods}

\section{Chemicals and Reagents}

Reference standards of acephate (purity 98.8\%) and methamidophos (purity 97.7\%) were procured from Sigma Aldrich Chemicals Pvt. Ltd, India. The formulation acephate $75 \%$ SP was obtained from the local market. Analytical-grade hexane, acetone, magnesium sulfate, anhydrous sodium sulphate, and anhydrous sodium acetate were procured from Ranbaxy Fine Chemicals, Bangalore, India. The HPLC grade acetonitrile used was procured from Spectrochem Pvt. Ltd, India. Primary secondary amine (PSA), particle size $40 \mu \mathrm{m}$, was procured from Agilent Technologies, Pvt. Ltd, India. Magnesium sulfate was activated by heating in a muffle furnace at $600^{\circ} \mathrm{C}$ for $6 \mathrm{~h}$ and kept in desiccators prior to use. Anhydrous sodium sulphate was activated in a hot air oven at $110^{\circ} \mathrm{C}$ for $6 \mathrm{~h}$ and kept in desiccators prior to use.

\section{Preparation of Standard Solutions}

Stock solutions of acephate and methamidophos $\left(500 \mu \mathrm{g} \mathrm{mL}^{-1}\right)$ were prepared in $\mathrm{n}$-hexane:acetone (9:1). Working standard solutions were prepared by further dilutions of the stock solutions. Calibration standards of acephate and methamidophos were prepared in the range of $0.003-1 \mu \mathrm{g} \mathrm{mL} \mathrm{mL}^{-1}$. Matrix matched standards were prepared by adding the insecticides to the blank extracts of brinjal and okra. A blank sample $(1 \mathrm{~mL})$ was evaporated to dryness under a stream of nitrogen using a Turbovap LV Concentration Workstation (Zymark Corporation, Hopkinton, MA, USA), and $1 \mathrm{~mL}$ of working standard solution was added at the required concentrations.

\section{Field Study}

The residue study of acephate on okra and brinjal was carried out at the experimental farm of I.I.H.R., Bangalore, India as per good agricultural practices (GAP) during December 2014 to March 2015. Acephate (75\% SP) application was given two times at two concentrations, i.e., standard dose $560 \mathrm{~g}$ a.i. ha ${ }^{-1}$ and double dose 1,120 $\mathrm{g}$ a.i. $\mathrm{ha}^{-1}$ of the formulated product. The first spray was given at the flowering stage; the next spray was given after 10 days. Five $5 \times 5 \mathrm{~m}$ plots were selected for every treatment and each treatment was replicated thrice. Untreated control was kept for comparison for both trials. Application of the pesticides was carried out using a knapsack sprayer. The spray volume used was $500 \mathrm{~L} \mathrm{ha}^{-1}$. Residues of acephate and methamidophos on brinjal and okra were analyzed on 0 (2 h), 1, 3, 5, 7, 10, 15, 20, 25, and 30 days after last spray.

Brinjal and okra samples were collected from each treated plot on every sampling day. Samples from three replicates were pooled together to make a sample size of approximately $5 \mathrm{~kg}$. A quarter of each brinjal and a part of each okra were added together to form a sub-sample of approximately $1 \mathrm{~kg}$. The samples were cut into small pieces and homogenized in a blender. The homogenized samples $(15 \mathrm{~g})$ in three replicates were used for analysis. Field soil was collected after 30 days. From each plot soil samples were collected at $0-15 \mathrm{~cm}$ depth and pooled together to make a sample size of approximately $5 \mathrm{~kg}$. The soil samples were air dried in the laboratory, powdered, and passed through a $2 \mathrm{~mm}$ sieve. Twenty gram representative sample in three replicates were used to analyze the insecticides.

\section{Sample Preparation, Extraction, and Clean up}

Brinjal and okra samples were extracted and purified according to the QuEChERS method. The homogenized sample $(15 \mathrm{~g})$ was weighed into a $50-\mathrm{mL}$ polypropylene centrifuge tube to which $15 \mathrm{~mL}$ HPLC grade acetonitrile was added. Anhydrous magnesium sulphate $(6 \mathrm{~g})$ and sodium acetate $(1.5 \mathrm{~g})$ was added to the tube and mixed thoroughly by spinning for $2 \mathrm{~min}$ in a vortex mixer. The 
tubes were centrifuged at 4,100 rpm for $10 \mathrm{~min}$ using a Restek centrifuge (Q-Sep 3000, Bellefonte, PA 16823, USA). The upper acetonitrile extract $(3 \mathrm{~mL})$ was placed in a $15-\mathrm{mL}$ polypropylene centrifuge tube and subjected to dispersive solid phase extraction (dSPE) clean-up. To the tube containing the samples we added $150 \mathrm{mg}$ PSA and $450 \mathrm{mg}$ anhydrous magnesium sulphate and shook vigorously for $1 \mathrm{~min}$. The tubes were centrifuged at $4,100 \mathrm{rpm}$ for $10 \mathrm{~min}$. One $\mathrm{mL}$ of the final acetonitrile extract was concentrated in a low volume concentrator (TurboVap LV concentration workstation) under nitrogen and re-dissolved in $1 \mathrm{~mL}$ of hexane:acetone (9:1). The samples were transferred to $1.5 \mathrm{~mL}$ chromatographic vials for analysis by GC and GC-MS.

A representative $20 \mathrm{~g}$ soil sample in triplicate was extracted using $30 \mathrm{~mL}$ acetonitrile:water (2:1) after shaking for $2 \mathrm{hrs}$ on a mechanical shaker and centrifuged in a Remi R-4 centrifuge at $10,000 \mathrm{rpm}$ for $10 \mathrm{~min}$. The solvent extract was placed in a measuring cylinder with stopper to which $10 \mathrm{~mL}$ of saturated sodium chloride solution was added. The measuring cylinder was tumbled to mix the contents thoroughly and kept for $3 \mathrm{hrs}$ to allow the layers to separate. Three $\mathrm{mL}$ of the upper acetonitrile layer was taken in a centrifuge tube and subjected to dSPE cleanup as described above. One $\mathrm{mL}$ of the acetonitrile extract was concentrated in a low volume concentrator under nitrogen and re-dissolved in $1 \mathrm{~mL}$ of hexane:acetone $(9: 1)$ for the analysis of acephate and methamidophos residues.

\section{Analysis by GC and GC-MS}

GC analysis of acephate and methamidophos was carried out using a Shimadzu gas chromatograph (model GC-2010) equipped with flame photometric detector (FPD) and an auto-sampler (Model AOC-20i). Capillary column DB-5MS (30 m $\times 0.25 \mathrm{~mm}, 0.25 \mu \mathrm{m}$ film thickness; stationary phase, $5 \%$ phenyl $/ 95 \%$ dimethylarylene siloxane) was used for analysis. The injector was kept at split mode with a split ratio of 10 . The column oven was initially maintained at $80^{\circ} \mathrm{C}$ with a hold time of $1 \mathrm{~min}$, increased at $15^{\circ} \mathrm{C} \min ^{-1}$ to $150^{\circ} \mathrm{C}$ with a hold time of $5 \mathrm{~min}$, increased at $4^{\circ} \mathrm{C} \mathrm{min}^{-1}$ to $250^{\circ} \mathrm{C}$ with a hold time of $5 \mathrm{~min}$. The temperatures of the injector and detector were maintained at $250^{\circ} \mathrm{C}$ and $290^{\circ} \mathrm{C}$, respectively. Ultra high pure nitrogen ( $99.999 \%$ purity) was used as the carrier gas at a flow rate of $1 \mathrm{~mL} \mathrm{~min}{ }^{-1}$. Ultra high pure hydrogen and zero air flow rates were maintained at 80 and $120 \mathrm{~mL} \mathrm{~min}^{-1}$, respectively. One $\mu \mathrm{L}$ of sample was injected using the auto-sampler. The retention times of acephate and methamidophos under the above operating conditions were 8.2 and $5.6 \mathrm{~min}$, respectively.

Confirmation of the presence of acephate and methamidophos in brinjal and okra samples was carried out by gas chromatography mass spectrometry (GC-MS). A Shimadzu GC-MS equipped with QP 2010 plus detector was operated in electron ionization (EI) mode at the ionization energy of $70 \mathrm{eV}$. Capillary column Restek, Rtx $(30 \mathrm{~m} \times 0.25 \mathrm{~mm}, 0.25 \mu \mathrm{m}$ film thickness; stationary phase, $14 \%$ cyanopropylphenyl $/ 86 \%$ dimethyl polysiloxane) was used for analysis. Ultra high pure helium (99.999\% purity) was used as carrier gas and the flow rate was $1 \mathrm{~mL} \mathrm{~min}^{-1}$. The $\mathrm{GC}$ was operated in splitless mode. The temperatures of the injector and ion source were at $250^{\circ} \mathrm{C}$ and $200^{\circ} \mathrm{C}$, respectively. Column oven temperature maintained was similar to that of GC analysis. Acephate and methamidophos analysis was carried out by scan mode and compared with the NIST database.

\section{Method Validation}

The analytical method was validated for analysis of acephate and methamidophos in brinjal, okra, and soil according to the guidelines for the method validation and quality control procedures for pesticide residue analysis in food and feed [18]. The method was validated based on such parameters as selectivity, accuracy and precision, linearity, limit of detection (LOD), limit of quantification (LOQ), matrix effect, and measurement uncertainty (MU). Accuracy was determined in terms of recovery. In order to estimate the accuracy of the method, recovery experiments were conducted by spiking pesticide-free samples of brinjal, okra, and soil with acephate and methamidophos individually. The spiking levels were $0.01,0.05,0.1,0.5$, and $1 \mathrm{mg} \mathrm{kg}^{-1}$ with six replications each. The precision of each compound was evaluated at five levels (0.01, $0.05,0.1,0.5$, and $\left.1 \mathrm{mg} \mathrm{kg}^{-1}\right)$. Six samples at each level for each matrix were analyzed in different days (intraand inter-day). Precision of the method was expressed as the percentage of relative standard deviation (\% RSD). Linearity was studied with six calibration points $(0.003$, $0.01,0.05,0.1,0.5$, and $1 \mu \mathrm{g} \mathrm{mL}-1)$ using standards prepared in organic solvents as well as in matrix-matched standards of brinjal, okra, and soil. The linearity curve was plotted with concentration versus instrument signal response. The LOQ was defined as the minimum level at which the analytes could be reliably detected at a signal:noise ratio of $\geq 10$. The LOD was determined by multiplying the standard deviation of the recoveries at the LOQ with student's t value at $99 \%$ confidence limit (SD $\left.\mathrm{LOQ} \times \mathrm{t}_{99}\right)$.

The measurement uncertainty is a parameter associated with the results of a measurement that expresses the dispersion of the true values. Uncertainty components associated with the potential sources were identified. The components were recovery, purity of the certified reference material, preparation of standard solutions, weight of sample taken for analysis, volume of solvent used, calibration of balance, and volumetric glass wares and temperature, etc. Relative uncertainty of each component was calculated. All individual uncertainties were computed and the combined uncertainty was estimated. The expanded uncertainty was determined by using the coverage factor $\mathrm{K}=2$ to give a confidence level of $95 \%$ [19]. Matrix interference is one of the major problems of pesticide residue analysis in food commodities. It may lead to reporting of false negative or false positive results. To avoid such problems, matrix matched standards were 
prepared as described above. Calibration curves were drawn and the same was used for quantification of the insecticides.

\section{Data Analysis}

The residue data was subjected to the first-order kinetic equation $\mathrm{Ct}=\mathrm{C}_{0} \mathrm{e}^{-\mathrm{kt}}$, where $\mathrm{C}_{\mathrm{t}}$ represents the concentration of pesticide at time $\mathrm{t}, \mathrm{C}_{0}$ represents the initial concentration, and $\mathrm{k}$ is the degradation rate constant. The half-life was calculated using the equation $t_{1 / 2}=\frac{\ln (2)}{k}$. The residue data were subjected to statistical analysis to determine preharvest interval as per Hoskins (1961) [20].

\section{Results and Discussion}

\section{Results of Method Validation}

Satisfactory results were obtained for all the validation parameters studied as per SANCO (2013) for analysis of acephate and methamidophos on brinjal and okra [18]. The recoveries of the two compounds from brinjal and okra are presented in Table 1. The recoveries of acephate were within $76.63-97.33 \%$, and that of methamidophos $81.62-99.50 \%$ from the three matrices, which were within the satisfactory range of $70-120 \%$ [18]. The precision (RSD) of the analytical method studied with six replicate measurements were within $3.3-11.8 \%$ for intraday analyses and $<15 \%$ for interday analyses. The calibration curve was linear in the range of 0.003-1.0 $\mu \mathrm{g}$ $\mathrm{mL}^{-1}$ for acephate and methamidophos and the correlation coefficients, $\left(\mathrm{R}^{2}\right)$, were $>0.99$. The method was highly selective as chromatographic peaks could be distinguished easily without interference from matrix peaks. The matrix effect was almost negligible as the analysis was carried out by GC-FPD. The LOD and LOQ of both compounds were 0.003 and $0.01 \mathrm{mg} \mathrm{kg}^{-1}$, respectively, in all the matrices. The combined uncertainties were within 9.9-17.5\%, indicating that the true value remained within this range. The uncertainties were highest at the LOQ level and decreased when the spiked concentration was increased.

\section{Residues of Acephate and Methamidophos on Brinjal and Okra}

Initial residue deposits of acephate on brinjal were 8.61 and $13.63 \mathrm{mg} \mathrm{kg}^{-1}$ from treatment at the standard and double doses of 560 and 1,120 g a.i. ha ${ }^{-1}$, respectively (Table 2). Acephate residues dissipated fast from brinjal but remained up to 25 and 30 days, respectively. Methamidophos residues were detected as initial residue deposits $\left(0.16\right.$ and $\left.0.29 \mathrm{mg} \mathrm{kg}^{-1}\right)$, which increased up to the third day and decreased afterward. Methamidophos residues were about $2 \%$ of the acephate residues initially, which increased to 57.4-67.6\%. Acephate degraded faster than methamidophos. Though methamidophos residue level was low compared to acephate, it remained on brinjal up to 25 and 30 days. The dissipation of acephate and methamidophos residues on brinjal is presented in Fig. 1. As the residue definition of acephate includes acephate and methamidophos, the residues of both compounds were added to study its dissipation behavior. The combined residues thus calculated were 8.77 and $13.92 \mathrm{mg} \mathrm{kg}^{-1}$ on 0-day. The residues (acephate + methamidophos) dissipated by about $21 \%$ after one day, $40.8-41.2 \%$ after three days, and about $82 \%$ after 10 days. After 15 days nearly $90 \%$ residues had dissipated from brinjal, but it persisted at a low level up to 25 and 30 days. From standard dose treatment the combined residues were $<$ LOQ after 30 days.

Initial residue deposits of acephate on okra were 8.44 and $15.05 \mathrm{mg} \mathrm{kg}^{-1}$ and that of methamidophos 0.14 and $0.21 \mathrm{mg} \mathrm{kg}^{-1}$ from treatments at the standard and double doses of 560 and 1,120 g a.i. ha ${ }^{-1}$, respectively (Table 3). Acephate residues dissipated gradually and remained on okra up to 15 and 20 days from treatments at the standard and double doses, respectively. Methamidophos residue levels increased up to the third day and decreased thereafter to remain for 15 and 20 days, respectively. Methamidophos formed 1.4-1.6\% of acephate initially, which increased up to $61-64 \%$ after seven days. The dissipation of acephate and methamidophos residues on okra is presented in Fig. 2. The combined residues (acephate + methamidophos) were 8.58 and $15.26 \mathrm{mg} \mathrm{kg}^{-1}$ on the 0 -day on okra. The residue dissipation from okra was a very fast process. After one

Table 1. Recovery of acephate and methamidophos from brinjal and soil at various spiked levels.

\begin{tabular}{|c|c|c|c|c|c|c|}
\hline \multirow{2}{*}{$\begin{array}{c}\text { Spiked } \\
\begin{array}{c}\text { concentration } \\
\left(\mathrm{mg} \mathrm{kg}^{-1}\right)\end{array}\end{array}$} & \multicolumn{2}{|c|}{ Okra } & \multicolumn{2}{c|}{ Brinjal } & \multicolumn{3}{c|}{ Soil } \\
\cline { 2 - 7 } & Acephate & Methamidophos & Acephate & Methamidophos & Acephate & Methamidophos \\
\cline { 2 - 7 } & $80.47 \pm 9.5$ & $84.23 \pm 8.7$ & $76.63 \pm 8.2$ & $81.62 \pm 7.7$ & $82.46 \pm 7.4$ & $84.05 \pm 9.1$ \\
\hline 0.01 & $88.36 \pm 8.8$ & $90.76 \pm 8.2$ & $80.95 \pm 6.2$ & $83.28 \pm 7.4$ & $86.03 \pm 6.6$ & $91.25 \pm 7.8$ \\
\hline 0.05 & $91.52 \pm 7.5$ & $96.40 \pm 7.3$ & $85.60 \pm 4.7$ & $88.03 \pm 6.4$ & $90.26 \pm 5.4$ & $92.08 \pm 6.7$ \\
\hline 0.10 & $93.80 \pm 6.2$ & $98.02 \pm 6.8$ & $89.34 \pm 3.5$ & $88.96 \pm 5.8$ & $93.48 \pm 4.1$ & $94.34 \pm 5.6$ \\
\hline 0.50 & $97.33 \pm 5.0$ & $99.50 \pm 4.5$ & $94.26 \pm 3.1$ & $91.72 \pm 4.9$ & $96.30 \pm 3.8$ & $95.78 \pm 4.3$ \\
\hline 1.00 & & & & & \\
\hline
\end{tabular}

*Average of six replicate analyses \pm SD 
Table 2. Residues of acephate and methamidophos on brinjal and soil.

\begin{tabular}{|c|c|c|c|c|c|c|c|}
\hline \multirow{3}{*}{$\begin{array}{c}\text { Days after } \\
\text { treatment }\end{array}$} & \multirow{3}{*}{$\begin{array}{l}\text { Untreated } \\
\text { control }\end{array}$} & \multicolumn{6}{|c|}{ Residues of acephate and methamidophos on brinjal $\pm \mathrm{SD}^{*}\left(\mathrm{mg} \mathrm{kg}^{-1}\right)$} \\
\hline & & \multicolumn{3}{|c|}{ Treatment at $560 \mathrm{~g}$ a.i. ha ${ }^{-1}$} & \multicolumn{3}{|c|}{ Treatment at $1120 \mathrm{~g}$ a.i. ha $^{-1}$} \\
\hline & & Acephate & Methamidophos & Total & Acephate & Methamidophos & Total \\
\hline 0 & ND & $8.61 \pm 0.12$ & $0.16 \pm 0.01$ & $8.77 \pm 0.13$ & $13.63 \pm 0.76$ & $0.29 \pm 0.03$ & $13.92 \pm 0.80$ \\
\hline 1 & ND & $6.47 \pm 0.44$ & $0.39 \pm 0.02$ & $\begin{array}{c}6.86 \pm 0.45 \\
(21.8)\end{array}$ & $10.31 \pm 0.55$ & $0.74 \pm 0.05$ & $\begin{array}{c}11.05 \pm 0.60 \\
(20.6)\end{array}$ \\
\hline 3 & ND & $4.56 \pm 0.24$ & $0.60 \pm 0.05$ & $\begin{array}{c}5.16 \pm 0.29 \\
(41.2) \\
\end{array}$ & $7.30 \pm 0.46$ & $0.94 \pm 0.02$ & $\begin{array}{c}8.24 \pm 0.48 \\
(40.8)\end{array}$ \\
\hline 5 & ND & $2.99 \pm 0.10$ & $0.49 \pm 0.03$ & $\begin{array}{c}3.48 \pm 0.14 \\
(60.3)\end{array}$ & $5.11 \pm 0.78$ & $0.69 \pm 0.10$ & $\begin{array}{c}5.80 \pm 0.89 \\
(58.3)\end{array}$ \\
\hline 7 & ND & $1.99 \pm 0.25$ & $0.29 \pm 0.03$ & $\begin{array}{c}2.28 \pm 0.27 \\
(74.0)\end{array}$ & $3.22 \pm 0.16$ & $0.55 \pm 0.04$ & $\begin{array}{c}3.77 \pm 0.21 \\
(72.9)\end{array}$ \\
\hline 10 & ND & $1.35 \pm 0.15$ & $0.26 \pm 0.02$ & $\begin{array}{c}1.61 \pm 0.18 \\
(81.6)\end{array}$ & $1.92 \pm 0.27$ & $0.45 \pm 0.05$ & $\begin{array}{c}2.37 \pm 0.33 \\
(82.9)\end{array}$ \\
\hline 15 & ND & $0.66 \pm 0.09$ & $0.23 \pm 0.02$ & $\begin{array}{c}0.89 \pm 0.11 \\
(89.8)\end{array}$ & $1.16 \pm 0.07$ & $0.30 \pm 0.03$ & $\begin{array}{c}1.46 \pm 0.10 \\
(89.5)\end{array}$ \\
\hline 20 & ND & $0.39 \pm 0.04$ & $0.10 \pm 0.01$ & $\begin{array}{c}0.49 \pm 0.05 \\
(94.4)\end{array}$ & $0.60 \pm 0.02$ & $0.18 \pm 0.02$ & $\begin{array}{c}0.78 \pm 0.04 \\
(94.4)\end{array}$ \\
\hline 25 & ND & $0.16 \pm 0.01$ & $0.09 \pm 0.01$ & $\begin{array}{l}0.25 \pm 0.02 \\
(97.1)\end{array}$ & $0.38 \pm 0.05$ & $0.13 \pm 0.01$ & $\begin{array}{c}0.51 \pm 0.06 \\
(96.33)\end{array}$ \\
\hline 30 & ND & $<\mathrm{LOQ}$ & $<$ LOQ & $<$ LOQ & $0.13 \pm 0.02$ & $0.09 \pm 0.01$ & $\begin{array}{c}0.22 \pm 0.03 \\
(98.4)\end{array}$ \\
\hline $\begin{array}{c}\text { Field soil } \\
\text { after } 30 \text { days }\end{array}$ & ND & $<\mathrm{LOQ}$ & $<\mathrm{LOQ}$ & $<$ LOQ & $<\mathrm{LOQ}$ & $<\mathrm{LOQ}$ & $<\mathrm{LOQ}$ \\
\hline
\end{tabular}

*Average of three replicate analyses \pm SD

Figures in the parenthesis are the percent dissipation of (acephate + methamidophos) residues. ND- Not detected

day, 18.7-21.8\% residues (acephate + methamidophos) had dissipated; this increased to $>50 \%$ after three days. After seven days, about $85 \%$ of residues had dissipated from okra. The combined residues reached $<$ LOQ after

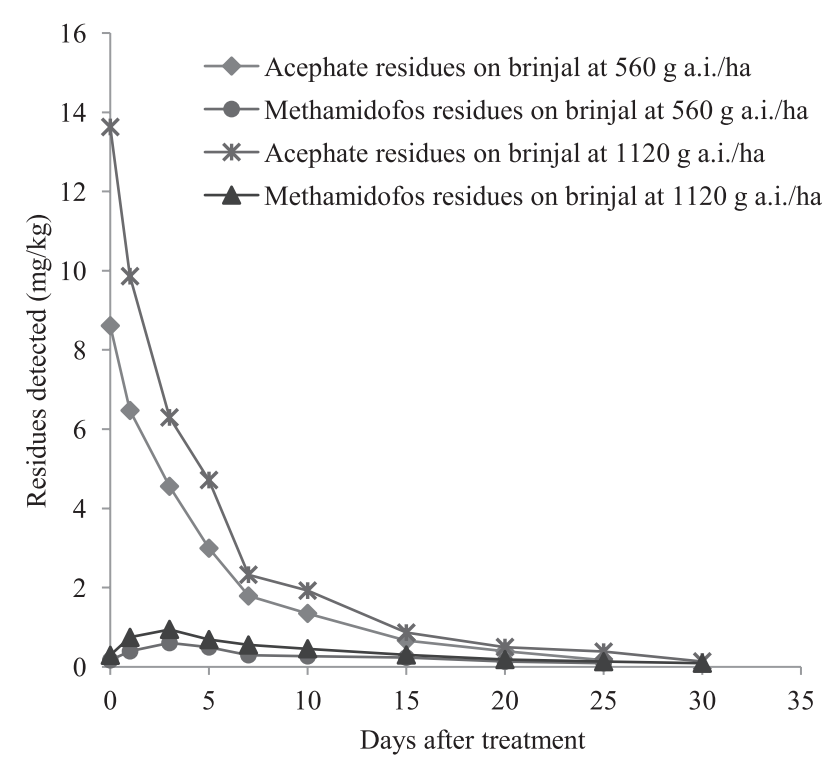

Fig. 1. Dissipation of acephate and methamidophos on brinjal.
20 and 25 days from treatments at the standard and double doses of 560 and $1,120 \mathrm{~g}$ a.i. ha ${ }^{-1}$, respectively. Methamidophos residue level was much lower than that of acephate, but it was detected in okra as long as acephate residues could be detected.

The initial residue levels of acephate were high on brinjal (8.61 and $\left.13.63 \mathrm{mg} \mathrm{kg}^{-1}\right)$ and okra (8.44 and $\left.15.05 \mathrm{mg} \mathrm{kg}^{-1}\right)$. In both studies acephate + methamidophos residues degraded faster in the initial stages of the study period (7-10 days), but remained on brinjal and okra for 30 and 20 days, respectively. Pesticides that penetrate into the fruit surfaces become solubilized in the plant waxes and dissipate slowly. Pesticides remaining on the surface of the plant may degrade faster and the amount adsorbed by the plant may degrade slowly. Being systemic insecticides, acephate and methamidophos may get adsorbed by brinjal and okra and reduce the amount available for degradation due to environmental factors [21]. Residues of acephate and its insecticidal metabolite methamidophos were detected in the fruit for up to four weeks after being given as trunk injection to avocado trees [22]. Between the two vegetables, acephate residues persisted longer on brinjal compared to okra. Brinjal is a slow-growing crop compared to okra. Depending on the variety, brinjal crop takes 70-85 days from transplanting to harvest and okra crop takes 55-65 days from sowing to harvest. The growth 
Table 3. Residues of acephate and methamidophos on okra and soil.

\begin{tabular}{|c|c|c|c|c|c|c|c|}
\hline \multirow{3}{*}{$\begin{array}{r}\text { Days after } \\
\text { treatment }\end{array}$} & \multirow{3}{*}{$\begin{array}{l}\text { Untreated } \\
\text { control }\end{array}$} & \multicolumn{6}{|c|}{ Residues of acephate and methamidophos on okra $\pm \mathrm{SD}\left(\mathrm{mg} \mathrm{kg}^{-1}\right)$} \\
\hline & & \multicolumn{3}{|c|}{ Treatment at $560 \mathrm{~g}$ a.i. $\mathrm{ha}^{-1}$} & \multicolumn{3}{|c|}{ Treatment at $1120 \mathrm{~g}$ a.i. ha ${ }^{-1}$} \\
\hline & & Acephate & Methamidophos & Total & Acephate & Methamidophos & Total \\
\hline 0 & ND & $8.44 \pm 1.09$ & $0.14 \pm 0.02$ & $8.58 \pm 1.12$ & $15.05 \pm 1.48$ & $0.21 \pm 0.02$ & $15.26 \pm 1.50$ \\
\hline 1 & ND & $5.28 \pm 0.88$ & $0.43 \pm 0.05$ & $\begin{array}{c}6.71 \pm 0.93 \\
(21.8)\end{array}$ & $11.71 \pm 1.75$ & $0.69 \pm 0.07$ & $\begin{array}{c}12.40 \pm 1.82 \\
(18.7)\end{array}$ \\
\hline 3 & ND & $3.21 \pm 0.66$ & $0.84 \pm 0.20$ & $\begin{array}{c}4.05 \pm 0.86 \\
(52.8)\end{array}$ & $6.04 \pm 0.76$ & $1.54 \pm 0.31$ & $\begin{array}{c}7.28 \pm 1.07 \\
(50.3)\end{array}$ \\
\hline 5 & ND & $1.60 \pm 0.25$ & $0.75 \pm 0.13$ & $\begin{array}{c}2.35 \pm 0.38 \\
(72.6)\end{array}$ & $3.46 \pm 0.33$ & $1.14 \pm 0.15$ & $\begin{array}{c}4.60 \pm 0.48 \\
(69.8)\end{array}$ \\
\hline 7 & ND & $0.72 \pm 0.12$ & $0.44 \pm 0.11$ & $\begin{array}{c}1.16 \pm 0.23 \\
(86.4)\end{array}$ & $1.33 \pm 0.21$ & $0.86 \pm 0.17$ & $\begin{array}{c}2.19 \pm 0.38 \\
(85.6)\end{array}$ \\
\hline 10 & ND & $0.32 \pm 0.04$ & $0.17 \pm 0.02$ & $\begin{array}{c}0.49 \pm 0.06 \\
(94.2)\end{array}$ & $0.78 \pm 0.18$ & $0.27 \pm 0.01$ & $\begin{array}{c}1.05 \pm 0.19 \\
(93.1)\end{array}$ \\
\hline 15 & ND & $0.15 \pm 0.02$ & $0.05 \pm 0.005$ & $\begin{array}{c}0.20 \pm 0.02 \\
\quad(97.6)\end{array}$ & $0.28 \pm 0.02$ & $0.16 \pm 0.01$ & $\begin{array}{c}0.44 \pm 0.03 \\
\quad(97.1)\end{array}$ \\
\hline 20 & ND & $<\mathrm{LOQ}$ & $<$ LOQ & $<$ LOQ & $0.08 \pm 0.007$ & $0.05 \pm 0.005$ & $\begin{array}{c}0.13 \pm 0.012 \\
(99.1)\end{array}$ \\
\hline 25 & ND & $<\mathrm{LOQ}$ & $<$ LOQ & $<\mathrm{LOQ}$ & $<$ LOQ & $<$ LOQ & $<$ LOQ \\
\hline $\begin{array}{c}\text { Field soil } \\
\text { after } 30 \text { days }\end{array}$ & ND & $<$ LOQ & $<$ LOQ & $<$ LOQ & $<$ LOQ & $<$ LOQ & $<$ LOQ \\
\hline
\end{tabular}

*Average of three replicate analyses \pm SD

Figures in the parenthesis are the percent dissipation of (acephate + methamidophos) residues.

ND - Not detected

dilution effect plays a major role in reducing pesticide residue levels in crops [23-24]. Reduced growth dilution effect may be a reason for longer persistence of acephate and methamidophos on brinjal. It has been reported by Antonious (1995) [25] that acephate persisted longer on capsicum (slow-growing crop) compared to cucumber (fast-growing crop).

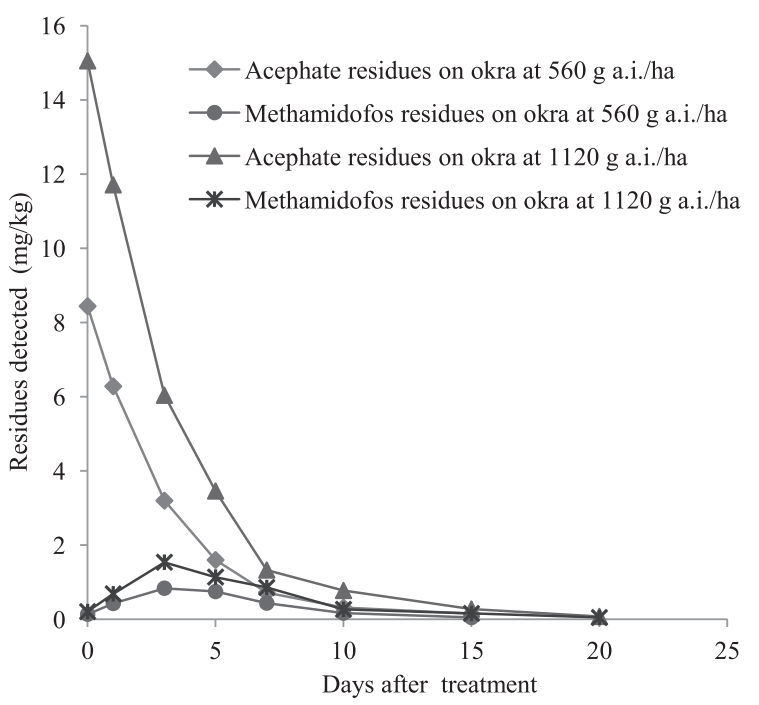

Fig. 2. Dissipation of acephate and methamidophos on okra.
In both studies a small amount of methamidophos was detected initially, which increased up to three days and was reduced thereafter. Concentration of methamidophos was $1.4-2.0 \%$ of acephate initially, which increased to 64-67.6\%. Methamidophos residue levels were lower compared to that of acephate, but it was more persistent compared to acephate. Deacetylation of acephate(formation of its metabolite) was detectable for one day following acephate treatment to capsicum [25]. As the application of acephate was given to brinjal and okra crops, the formation of methamidophos was expected only through metabolism of acephate. When acephate was applied to olive, methamidophos residues were always detected [26]. Residues of methamidophos were detected in all samples of tomatoes except those for 0 day [27]. Acephate and methamidophos are systemic in nature and highly water soluble. Acephate penetrates into the fruit, where it is transformed to methamidophos [28]. Methamidophos was found to be more persistent than acephate [29]. Transformation of acephate to methamidophos and the persistent nature of methamidophos could be the reason for detection of methamidophos up to 30 days in brinjal and okra.

\section{Residues in Soil}

Acephate and methamidophos residues were not detected in the field soil after 30 days. In the current study 
the application of acephate was given to the brinjal and okra plants. The possibility of acephate residues in the soil was from spillage of spray solutions and spray drift during application. The thick foliage of brinjal and okra plants could have prevented excessive spillage of spray solutions. The residues in soil could have degraded as the half-lives for acephate in topsoils were only 0.4 to 2.6 days [30]. The crops were irrigated at regular intervals and acephate could have leached underground as it is highly soluble in water. The dissipation rate of acephate and methamidophos in soil was increased with increasing soil moisture content [31]. Acephate is poorly sorbed to soil, thus the risk of leaching to the aquatic environment is high [32]. Degradation of acephate in soil can happen due to the presence of soil microorganisms [33]. The combination of all the above factors could be responsible for acephate degradation in the field soil.

\section{Dissipation Kinetics}

Dissipation of acephate (acephate + methamidophos) followed first-order kinetics, which could be described by fitting the data into the equation $\mathrm{Ct}=\mathrm{C}_{0} \mathrm{e}^{\mathrm{ekt}}$. The halflife of degradation $\left(\mathrm{DT}_{50}\right)$ was expressed as the time within which the concentration was reduced by $50 \%$. The combined residues dissipated at the half-lives of 5.0 and 5.2 days from brinjal; 2.7 and 3.0 days from okra from treatments at the standard and double doses of 560 and $1,120 \mathrm{~g}$ a.i. $\mathrm{ha}^{-1}$, respectively. The shorter half-life on okra compared to brinjal could be attributed to the fast-growing nature of the okra crop, where dilution of the insecticide due to growth was more. The half-life of acephate was 3.7 days on cucumber fruits compared to six days on capsicum fruits [25]. On mango the reported half-life of acephate was five days, and it was eight days on cotton plant [34-35]. PHI is the elapsed time gap between the last spray application to a crop and the first harvest. This time is given to allow the residues in the crop to dissipate to below its MRL. The pre-harvest interval (PHI) was calculated as per statistical analysis by Hoskins (1961) [20]. The prescribed MRL for acephate and methamidophos residues on brinjal and okra is $0.01 \mathrm{mg} \mathrm{kg}^{-1}$ [36]. The PHIs thus calculated for the combined residues of acephate and methamidophos to reduce below MRL were 47 and 53 days for brinjal and 25 and 31 days for okra, for treatments at the standard and double doses, respectively. The PHI of acephate varied widely on different crops. On capsicum the PHI was 12 days in the open field and 16 days under controlled environmental conditions [37]. The required PHI for mango was 30 days [34].

\section{Conclusion}

The analytical method was suitable for analysis of acephate and methamidophos in brinjal and soil at the MRL ( $\left.0.01 \mathrm{mg} \mathrm{kg}^{-1}\right)$. The recoveries of both compounds were within the satisfactory range. Acephate residues from the standard dose treatment of $560 \mathrm{~g}$ a.i. ha $^{-1}$ persisted on brinjal and okra for 25 and 15 days, respectively. Methamidophos, the metabolite of acephate, was detected up to 25 and 15 days. Though methamidophos residue level was lower compared to acephate, it was detected in brinjal and okra as long as acephate was detected. Acephate is rapidly translocated from soil to plant and translocation occurs in the direction of roots to foliage, not from foliage to root [38]. But the chances of acephate entering into successive crops was ruled out as the field soil was free from residues of acephate and methamidophos after 30 days. The combined residues of acephate and methamidophos degraded at the half-life of 5.0-5.2 days on brinjal and 2.7-3.0 days on okra. At the standard dose treatment the PHI required for the residues to dissipate below MRL was 47 days for brinjal and 25 days for okra. Therefore, the application of acephate should be given at the early stages of crop growth to avoid having residues above MRL in the harvested produce.

\section{Acknowledgements}

The authors thank the director of the Indian Institute of Horticultural Research, Bangalore, India for providing the facilities to carry out this work.

\section{References}

1. BAJAD V.V., SINGH H.P., PATIL S.C. Efficacy of chemical insecticides against shoot and fruit borer, Earias vittella (Fab.) on okra. Trends Biosci. 7 (14), 1644, 2014.

2. VEVAI E.J. Know your crop its pest problems and control-25: Brinjal. Pesticides, 4, 26, 1970.

3. DUARA B., BARUAH A.A.L.H., DEKA S.C., BARMAN N. Residues of cypermethrin and fenvalerate on Brinjal. Pestic. Res. J. 15 (1), 43, 2003.

4. TIWARI G., PRASAD C.S., NATH L. Integrated management of brinjal shoot and fruit borer, (Leucinodes orbonalis Guenee) in Western Uttar Pradesh. Annals Hort. 2, 54, 2009.

5. PARDESHI A.M., BHARODIA R.K., JETHVA D.M., RATHOD R.T., PATEL P.V. Bioefficacy of chemical insecticides against Earias vittella (Fabricius) on okra. Agric. Sci. Digest. 31 (1), 25, 2011.

6. TOMLIN C. The pesticide manual, $10^{\text {th }}$ edn. The Royal Society of Chemistry, Cambridge, 1341, 1995.

7. ROBERTS T.R., HUTSON D.H. Acephate. Metabolic Pathways of Agrochemicals - Part 2: Insecticides and Fungicides. The Royal Society of Chemistry, Cambridge, UK, 201, 1999.

8. REIGART J.R., ROBERTS J.R. Organophosphate Insecticides. Recognition and Management of Pesticide Poisonings, $5^{\text {th }}$ ed.; U.S. Environmental Protection Agency, Office of Prevention, Pesticides and Toxic Substances, Office of Pesticide Programs; U.S. Government Printing Office: Washington, DC, 34, 1999.

9. RADHAKRISHORE R.K., SINGH T.K., SHAH M.A.S. Efficacy of certain insecticides against brinjal shoot and fruit borer, Leucinodes orbonalis Guen in Manipur. J. Exp. Zoology India 17 (2), 551, 2014.

10. TRIPATHY N.N. Efficacy of different insecticides and neem leaf extracts against brinjal shoot fruit borer, 
(L. orbonalis G.). Paper presented in: National Conference on Applied Entomology held at R.C.A., Udaipur, 116, 2005.

11. TOMAR R.K.S., Efficacy and economics of biopesticide and insecticide combinations against okra shoot and fruit borer. Indian J. Entomol. 60 (1), 25, 1998.

12. YADAV A., RAGHURAMAN M. Bioefficacy of certain newer insecticides against fruit and shoot borer, Leucinodes orbonalis (Guen.), white fly, bemisia tabaci (Genn.), and jassid, Amrasca devastans distant in brinjal. Proceedings of National Conference on Harmony with Nature in Context of Environmental Issues and Challenges of the $21^{\text {st }}$ Century (HORMONY - 2014), Udaipur, India, November 28-30, 2014.

13. CHOUDHARY A., SHARMA D.C. Pesticide residues in honey samples from Himachal Pradesh (India). Bull. Environ. Contam. Toxicol. 80 (5), 417, 2008.

14. SHAIK S., SHOBHA S. Pesticide residues in spices of Guntur district of Andhra Pradesh. J. Res. ANGRAU. 40 (3), 99, 2012.

15. WEIHAO L., LINGYU T., JIANXIA L., ZIKUAN G., GUOTAO D. Monitoring of pesticide residues levels in fresh vegetable from Heibei Province, North China. Environ. Monit. Assess. 186 (10), 6341, 2014.

16. 16. FEN Z., LI J. Progressing on toxicity and residue analysis of methamidophos. J Traditional Chinese Vet. Med. 21 (5), 40, 2003.

17. KAUR R., KAUR S., MANDAL K., SINGH B. Dissipation behavior and risk assessment of acephate in brinjal using GLC with FPD. Environ. Monit. Assess. 187 (2), 36, 2015.

18. SANCO, Guidance document on analytical quality control and validation procedures for pesticide residues analysis in food and feed (SANCO/12571/2013), 1, 2013.

19. EURACHEM CITAC Guide CG 4, Quantifying Uncertainty in Analytical Measurement 4, 2012.

20. HOSKINS W.M. Mathematical treatment of loss of pesticide residues. Plant Protec. Bull. 9, 163, 1961.

21. HOLLAND J., SINCLAIR P. In Pesticide Residues in Food and Drinking Water Human Exposure and Risks, edited by D. Hamilton and S. Crossley (John Wiley \& Sons Ltd, England), 2004.

22. BYRNE F.J., URENA A.A., ROBINSON L.J., KRIEGER R.I., DOCCOLA J., MORSE J.G. Evaluation of neonicotinoid, organophosphate and avermectin trunk injections for the management of avocado thrips in California avocado groves. Pest Manag. Sci. 68 (5), 811, 2012.

23. JURASKE R., FANTKE P., RAMÍREZA.C.R., GONZÁLEZ A. Pesticide residue dynamics in passion fruits: comparing field trial and modelling results. Chemosphere 89 (7), 850, 2012.

24. XIA H.L., WANG Y.G., WAN H.B., MA H.Q., CHEN Z.M. Growth dilution by tea plants during the degradation of pesticides in tea plants. J. Tea Sci. 12 (1), 1, 1992.
25. ANTONIOUS G.F. Analysis and fate of acephate and its metabolite, methamidophos, in pepper and cucumber J. Environ. Sci. Health, Part B 30 (3), 377, 1995.

26. CABRAS P., ANGIONI A., GARAU V.L., PIRISI F.M., CABITZA F., PALA M. Acephate and buprofezin residues in olives and olive oil Food Addit. Contam. 17 (10), 855, 2000.

27. LEIDY R.B., SHEETS T.J., SORENSEN K.A. Residues of acephate and methamidophos in greenhouse tomatoes. J. American Soc. Hort. Sci. 103 (3), 392, 1978.

28. SANZ-ASENSIO J., MARTINEZ-PRADO A.P., PLAZAMEDINA M., MARTINEZ-SORIA M.T., PEREZ-CLAVIJO M. Behaviour of acephate and its metabolite methamidophos in apple samples. Chromatographia, 49 (3), 155, 1999.

29. ZHIQIANG K., FENGSHOU D., JUN X., XINGANG L., JING L., YUANBO L., YINGYING T., LIQUN G., WEILI S., YONGQUAN Z. Degradation of acephate and its metabolite methamidophos in rice during processing and storage. Food Control. 23 (1), 149, 2012.

30. CHAI L.K, MOHD-TAHIR N., HANSEN S., HANSEN H.C.B. Dissipation and leaching of acephate, chlorpyrifos, and their main metabolites in field soils of Malaysia. J.Environ. Qual. 38 (3), 1160, 2009.

31. JUIHUNG Y., KUOHSIUNG L., YEISHUNG W. Potential of the insecticides acephate and methamidophos to contaminate groundwater. Ecotoxicol. Environ. Saf. Section B. 45 (1), 79, 2000.

32. CHAI L.K., MEEHUA W., MOHD-TAHIR N., HANSEN H.C.B. Degradation and mineralization kinetics of acephate in humid tropic soils of Malaysia. Chemosphere. 79 (4), 434, 2010.

33. RAMU S., SEETHARAMAN B. Biodegradation of acephate and methamidophos by a soil bacterium Pseudomonas aeruginosa strain Is-6. J. Environ. Sci. Health Part B. 49 (1), 23, 2014.

34. MOHAPATRA S., AHUJA A.K., DEEPA M., SHARMA D. Residues of acephate and its metabolite methamidophos in/on mango fruit (Mangifera indica L.). Bull. Environ. Contam. Toxicol. 86 (1), 101, 2011.

35. BOUCHARD D.C., LAVY T.L. Fate of acephate in the cotton plant. J. Econom. Entomol. 75 (5), 921, 1982.

36. EU Pesticides database: http://ec.europa.eu/food/plant/ pesticides/eu-pesticides-database/public/?event=pesticide. residue.CurrentMRL\&language $=E N$. Accessed 1 December 2015.

37. SHARMA D., HEBBAR S.S., DIVAKARA J.V., MOHAPATRA S. Residues of pesticides acephate and methamidophos in capsicum grown in greenhouse and open field. Qual. Assur. Saf. Crops Foods. 4 (5), 33, 2012.

38. WHO. Pesticide residues in food - Acephate; International Programme on Chemical Safety, World Health Organization: Geneva, Switzerland, 1976. 